\title{
Apropriação tecnológica da produção integrada de pêssegos na região de Pelotas no Estado do Rio Grande do Sul
}

\author{
Technological appropriation of the integrated peach production in the region of Pelotas in the \\ State of Rio Grande do Sul
}

\author{
Silon Junior Procath da Silva ${ }^{I}$ Volnei Krause Kohls ${ }^{I I}$ Roberta Manica-Berto ${ }^{\text {II }}$ \\ Paulo Rigatto ${ }^{\mathrm{II}}$ Cesar Valmor Rombaldi ${ }^{\mathrm{IV}}$
}

\section{RESUMO}

\begin{abstract}
A produção integrada de pêssego (PIP) teve seu marco inicial no Brasil em 1999. Este estudo analisou o nível tecnológico no qual encontram-se os produtores de pêssego, identificando a taxa de adoção dos sistemas de produção integrada (PI), buscando evidenciar os fatores determinantes de sua validação. Para isso, foi realizada a aplicação de questionário semi-estruturado a 20 produtores de pêssego, nos quais foram levantadas informações das unidades de produção relacionadas à sua caracterização e tecnologia de produção, no período de 2006 a 2007. Os principais fatores apontados como limitantes para a gestão da PIP foram: o pouco conhecimento sobre a norma da PIP; a restrita lista de agrotóxicos registrados para utilização pela cultura; e a falta de diferenciação e remuneração do pêssego produzido sob as normas da PI. Os pontos detectados como positivos foram: a identificação do aumento do interesse sobre a PIP por parte dos produtores, com destaque para a identificação dos benefícios ambientais e de proteção do produtor e a redução do uso de insumos externos (especialmente agrotóxicos) e de operações de manejo do solo.
\end{abstract}

Palavras-chave: alimentos seguros, qualidade de frutas, nível tecnológico.

\section{ABSTRACT}

The integrated production of peach (IPP) had its first milestone in Brazil in 1999. This study examined the technological level in which are producers of peach, identifying the rate of adoption of integrated production systems (IP), seeking to highlight the determinants of its validation. For this, a semi-structured questionnaire was performed with 20 peach producers, in which were raised information about the production units regarding its characterization and production technology, in the period from 2006 to 2007. The main factors identified as limiting for the management of IPP were: little knowledge about standard IPP, restricted list of pesticides registered for agriculture use, lack of differentiation and return on peach produced under the rules of IP. The points detected as positive were: identification of increased interest on MIP by producers, with emphasis on: identifying the environmental benefits and protection of the producer, reduction of external inputs (particularly pesticides) and soil management operations.

Key words: safe food, fruit quality, technological level.

\section{INTRODUÇÃO}

No Brasil, o marco da PIF está associado à implementação desse sistema na produção de maçã, em 1998 (PROTAS, 2003), seguida pela produção de pêssegos em 1999 (FACHINELLO et al., 2005). No contexto internacional, a PIF é um sistema compulsório (CHEVRIN, 2002). Associada à PIF, a rastreabilidade se constitui no complemento para que sejam atendidas as normativas exigidas pela legislação, bem como para satisfazer às demandas do mercado, principalmente do ponto de vista da oferta de alimento seguro (food

\footnotetext{
'Departamento de Defesa Fitossanitária, Centro de Ciências Rurais, Universidade Federal de Santa Maria (UFSM), Campus Universitário, 97105-900, Camobi, Santa Maria, RS, Brasil. E-mail: silonjunior@gmail.com. Autor para correspondência.

"Departamento de Ciências Sociais Agrárias, Faculdade de Agronomia Eliseu Maciel (FAEM), Universidade Federal de Pelotas (UFPel), Pelotas, RS, Brasil.

"IIPós-doutorado em Fitossanidade, FAEM, UFPel, Pelotas, RS, Brasil.

${ }^{\text {IV }}$ Departamento de Ciência e Tecnologia Agroindustrial, FAEM, UFPel, Pelotas, RS, Brasil.
} 
safety), produzido de forma ambientalmente sustentável, com qualidade superior, e protegendo a saúde do produtor e do consumidor (FACHINELLO et al., 2001; FACHINELLO et al., 2005; ROMBALDI et al., 2007).

Embora com princípios e pressupostos em consonância com as tendências mundiais da fruticultura, não há massiva apropriação do sistema de PI na produção de pêssegos. Uma das hipóteses para esse fato é de que ainda há falta de conhecimento acerca do sistema, tal como a eficiência e a eficácia, e da viabilidade técnica e, sobretudo, econômica de algumas práticas recomendadas, principalmente daquelas relacionadas ao monitoramento de insetospraga e doenças, ao preparo e aplicação de agrotóxicos e afins e custos referentes à rastreabilidade, além de auditorias, tendo em vista que inovações nos sistemas produtivos aumentam as oportunidades de lucro (BRESSER PEREIRA, 2006). Além disso, acredita-se que o sistema, embora proporcionador de ganhos ambientais pela diminuição do uso de agrotóxicos, manutenção da cobertura de solo, entre outras técnicas preconizadas pelas normas da Produção Integrada de Pêssego (PIP), e dos ganhos econômicos proporcionados pelo menor número de pulverizações, ainda não foi validado pela maioria dos produtores da região estudada, que produz pêssego predominantemente para a indústria de conserva. A não validação do sistema de PIP, por parte do produtor, se dá pelanão percepção de ganhos econômicos, pela complexidade das operações geradas pelo monitoramento de pragas. Além disso, a necessidade de registro de todas as operações do pomar em caderneta de campo, o que é fundamental para a rastreabilidade, e também por que a etapa de certificação viria a onerar a atividade agrícola contribui para a não validação da mesma (TIBOLA et al., 2008). Com essas considerações, parte-se da hipótese de que, assim como o sistema, também seu conceito, seus pressupostos e vantagens, não foram percebidos pelos consumidores e a PIP ainda não representa um diferencial para a comercialização, nos mercados atualmente explorados pelos produtores estudados.

Para testar essa hipótese, o trabalho teve por objetivos analisar a massificação do sistema PIP de forma certificada, avaliar a apropriação dos conceitos relacionados no mercado da região de Pelotas, além dos possíveis problemas tecnológicos e de mercado, pondo em evidência os principais fatores positivos e limitadores para a sua adoção e validação.

\section{MATERIAL E MÉTODOS}

Para testar a hipótese, as etapas desenvolvidas no trabalho se constituíram em elaboração do instrumento de coleta (IC), validação do IC, adequação e aplicação do IC e análise dos dados, considerando a aplicação de cada pergunta de forma individual.

A fonte para coleta de dados foi o conjunto de gestores dos pomares que constituíram o objeto de estudo. Trata-se de um estudo de múltiplos casos (20 propriedades) com uma unidade de análise (Produção Integrada de Pêssego - PIP).

Fez-se a seleção dos produtores de modo a ter um perfil diverso, sendo 12 com menos de 10 hectares de pomar, cinco com pomares entre 10 e 20 hectares, três produtores com mais de 20 hectares, de modo a estarem contemplados os perfis de produtores existentes na região. Nesse universo, optou-se por quatro perfis de produtores quanto ao relacionamento com órgãos de geração e difusão de conhecimento: produtores que recebem assistência da Emater-RS; produtores que participam de trabalhos junto ao Programa de Pós-graduação em Fruticultura da FAEM/ UFPel e/ou Embrapa; aqueles que possuem assistência direta de empresas processadoras de pêssego, podendo um produtor se encaixar em mais de um dos casos e, por último; produtores sem nenhum tipo de relacionamento com essas instituições.

Assim, através desta pesquisa, procurouse entender como ocorre a apropriação do conhecimento inerente à PIP, entre as instituições de pesquisa e extensão e os produtores, bem como identificar as principais características/inflexões/ divergências da relação pesquisador-extensionistaprodutor rural.

Optou-se pelo modelo de questionário semiestruturado com 52 questões, de modo a verificar os principais pontos, cuja informação existente na literatura sobre PIP não contemplava as principais dúvidas existentes, na opinião do grupo de pesquisa, mas, ao mesmo tempo, permitia ao produtor a plena expressão de sua opinião/análise quanto à eficiência e eficácia da PIP, bem como de sua viabilidade técnica e econômica. Esse procedimento foi baseado em trabalhos prévios, como os de REIS \& FORCELLINI (2006).

Coletaram-se dados relacionados ao nível tecnológico de adoção da PIP, cultivares, uso de defensivos, qualificação da mão-de-obra e do produtor, uso de atrativos, monitoramento de pragas e assistência técnica e relacionamento com órgão de pesquisa, correspondentes às atividades realizadas no ano agrícola 2006/2007 e relativos à unidade de 
produção. Essa coleta de dados ocorreu entre $1^{\circ}$ de dezembro de 2006 e 1o de junho de 2007, na região de Pelotas, no Estado do Rio Grande do Sul, com produtores de pêssego para indústria e para consumo in natura. Os agricultores participantes foram escolhidos a partir de uma lista prévia elaborada com auxílio de pesquisadores da UFPel, Embrapa, extensionistas da EMATER, representantes da Indústria, dos produtores e do varejo. A partir dessa definição da lista preliminar, feita pela equipe do projeto em conjunto com as instituições, contendo 103 produtores, a equipe do projeto escolheu aqueles que seriam entrevistados para a pesquisa, originando a relação de produtores final, inluindo os critérios de área, tipo de produção e tipo de assistência.

$\mathrm{Na}$ questão estruturada, foi dada ao produtor a possibilidade de escolha de alternativa em relação aos motivos pelos quais os produtores não adotam produção integrada através de fichas de visão aleatória, de mais de um motivo, citando por ordem decrescente de importância, ou seja, daquele de maior ao de menor importância, aqueles fatores que mais impactam a produção de pêssego da propriedade. Atribuiu-se nota máxima igual ao número de opções oferecidas $(\mathrm{N})$, à segunda considerada mais importante recebia nota $\mathrm{N}-1$ e assim sucessivamente. Fatores não apontados como importantes pelo produtor receberam nota zero. Assim, a importância dada ao item era a soma da nota obtida junto a todos os produtores, considerando-se como mais importante aquele que obteve a maior soma. O detalhamento dos formulários está em arquivo e pode ser remetido via mail para todos aqueles que solicitarem. A avaliação qualitativa dos resultados obtidos considerou a análise conjunta dos dados oriundos da aplicação de cada pergunta individualmente.

\section{RESULTADOS E DISCUSSÃO}

Dentre as principais cultivares de pêssego utilizadas (Tabela 1), há predominância daquelas do tipo indústria em relação às de duplo propósito, devido ao fato de os produtores da região de Pelotas destinarem, majoritariamente, a produção para o processamento industrial. Tal fato ocorre por ser ainda recente a exploração do mercado da fruta in natura pelos produtores da região e por essa alternativa ainda representar baixos volumes. Embora o pêssego 'Granada' seja do tipo indústria, também é muito utilizado para consumo in natura, por apresentar película com cor de recobrimento avermelhada, a qual torna o produto atraente na visão dos consumidores (EMBRAPA, 2005). Entretanto, essa cultivar tem apresentado alternâncias de produção, ao longo dos anos, na região sul do RS, onde é mais cultivada, resultando em frequentes reclamações entre os produtores entrevistados. Por exemplo, na safra 2006/ 2007, com a ocorrência de chuvas e geadas tardias em meados de agosto, período em que essa cultivar floresce, houve redução significativa da produtividade da maioria dos pomares, sugerindo que, ou os produtores não têm "alimentado" a pesquisa com dados precisos ou a informação correta, quanto à revisão da descrição de cultivares, não tem chegado ao produtor.

Dos 20 produtores entrevistados, somente um, com menos de 10ha de área de pomar, que vende sua produção exclusivamente para a indústria e sem assistência técnica, declarou que nunca havia ouvido

Tabela 1 - Cultivares, área média, frequência e percentagem sobre a área total das 10 principais cultivares de pêssego.

\begin{tabular}{lcccc}
\hline Cultivar & Área média (ha) & Frequência & Total (ha) & $\%$ sobre área total \\
\hline 'Granada'* & 9,78 & 16 & 156,50 & 19,97 \\
'Esmeralda'* & 9,02 & 14 & 126,25 & 16,10 \\
'Maciel'** & 6,96 & 12 & 83,50 & 10,65 \\
'Jubileu'* & 6,94 & 12 & 83,25 & 10,63 \\
'Eldorado'** & 5,15 & 10 & 51,50 & 6,58 \\
'Jade'* & 5,72 & 8 & 45,75 & 5,84 \\
'Leonense'** & 5,75 & 6 & 34,50 & 4,41 \\
'Sensação'* & 3,50 & 9 & 31,50 & 4,03 \\
'Precocinho'* & 14,50 & 2 & 29,00 & 3,68 \\
'BR6'* & 4,14 & 7 & 29,00 & 3,68 \\
Outras (14) & 3,06 & 4 & 113,25 & 14,43 \\
Média & 7,84 & 5,15 & - & - \\
Total & - & 20 & 784 & 100 \\
\hline
\end{tabular}

*Pêsssego tipo indústria ** Pêssego tipo dupla finalidade - Fonte: elaboração do autor com dados da pesquisa.

Ciência Rural, v.41, n.9, set, 2011. 
falar em PIP. O elevado percentual de produtores com informações acerca da PIP evidencia que há difusão da informação, já que 19 produtores (95\%), de alguma forma, conheciam os conceitos da PIF e da PIP. Isso indica que a ação institucional, no que concerne à popularização dos conceitos junto aos produtores, vem atuando adequadamente quanto à difusão do conhecimento gerado. Quanto à assimilação dos conceitos técnicos da PIP, verificou-se que os produtores a relacionam principalmente com o uso controlado de agrotóxicos, sendo este o aspecto mais apontado. Tal fato vai ao encontro das afirmações realizadas por TIBOLA et al. (2005) que obtiveram menores danos causados por insetos-praga e menor número de pulverizações de inseticidas na PIP, sendo essa uma das informações amplamente citadas nas reuniões e encontros técnicos dessa temática.

Ao questionar os produtores a respeito do motivo pelo qual não possuem interesse em adotar a PIP certificada (Figura 1), ficou evidente que as estratégias, que visam massificar a adoção desta, devem concentrar-se em demonstrar ao produtor os ganhos econômicos, com a adoção dessa tecnologia, e em aumentar o nível de informação sobre o sistema. Um dos aspectos fundamentais para o potencial de sucesso é o fato de que nenhum dos produtores entrevistados vê fortes barreiras técnicas para adotar PIP. Comportamento similar também foi evidenciado na União Europeia (CHEVRIN, 2002).

As principais vantagens apontadas pelos produtores, como motivadoras para a adoção da PIP, foram melhor qualidade da produção obtida e preocupações com a saúde do produtor e de sua família.
Tal fato está de acordo com o demonstrado por NUNES et al. (2004) e FACHINELLO et al. (2005), que, em pomares sob PI, obtiveram frutos de melhor qualidade em comparação com aqueles sob Produção Convencional (PC). Nota-se que, espontaneamente, somente um produtor, que possuiu mais de 20 hectares e participou de trabalhos de pesquisa da UFPel, afirmou que a redução de custos foi fator importante como resultado da adoção da PIP e apenas dois, também com mais de 20 hectares de pomar, um com assistência técnica da indústria e outro que participou de trabalhos da Universidade, afirmaram que a tecnologia é mais rentável (Tabela 2). Assim, ações que visem demonstrar ao persicultor a maior viabilidade técnica e econômica da PIP, em comparação à tecnologia tradicional de manejo do pomar, devem ser incentivadas de modo a fomentar sua adoção.

A pouca valorização da PIP pelo mercado é apontada como fator limitante para a evolução do sistema (Tabela 2). Embora os benefícios validados sejam consistentes, dificilmente haverá massificação do uso enquanto essa consistência não for percebida plenamente. Essa diferenciação não, necessariamente, precisa ser na forma de preço final do produto, mas como destaque na forma de apresentação e/ou requisito preferencial no ato de intenção de compra.

Os produtores mencionaram, com frequência, que uma das dificuldades de manejo é a restrita lista de princípios ativos registrados para o manejo de pragas na cultura. De forma enfática, os produtores indagaram: "por que há tantos produtos registrados para a maçã e não para o pêssego, se as pragas são praticamente as mesmas e os frutos são

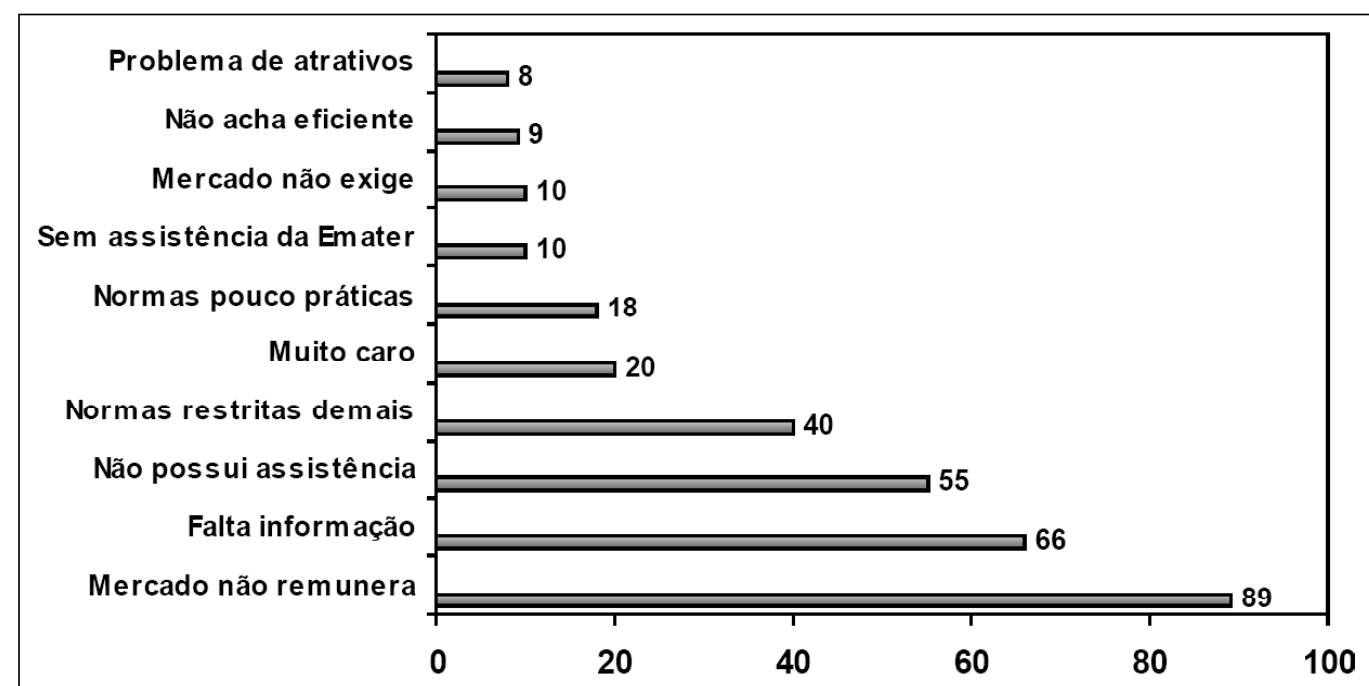

Figura 1 - Motivos pelos quais os produtores não adotam a produção integrada de pêssego certificada, conforme o grau de importância em ordem decrescente. 
Tabela 2 - Motivos para estar ou não na produção integrada apontadas, espontaneamente, pelos produtores.

\begin{tabular}{lllllllllllllllllllll}
\hline & $* \mathrm{a}$ & $\mathrm{b}$ & $\mathrm{c}$ & $\mathrm{d}$ & $\mathrm{e}$ & $\mathrm{f}$ & $\mathrm{g}$ & $\mathrm{h}$ & $\mathrm{i}$ & $\mathrm{j}$ & $\mathrm{l}$ & $\mathrm{m}$ & $\mathrm{n}$ & $\mathrm{o}$ & $\mathrm{p}$ & $\mathrm{q}$ & $\mathrm{r}$ & $\mathrm{s}$ & $\mathrm{t}$ \\
\hline Respostas & 6 & 6 & 4 & 2 & 2 & 5 & 3 & 6 & 1 & 8 & 1 & 1 & 6 & 2 & 1 & 2 & 1 & 1 & 2 \\
$\%$ & 30 & 30 & 20 & 10 & 10 & 25 & 15 & 30 & 5 & 40 & 5 & 5 & 30 & 10 & 5 & 10 & 5 & 5 & 10 \\
\hline
\end{tabular}

*a - Não fazer PI; b - Maior qualidade da produção; c - Saúde; d - Quando for exigência do mercado; e - Mais rentável; f - Garantir mercado; $g$ - Consciência; $h$ - Economia de defensivos; $i$ - Menor custo; $j$ - Sem motivo; 1 - Problema de atrativos; $m$ - Doenças; $n$ Mercado não exige; o - Falta assistência; $p$ - Falta de divulgação; q - Falta de acompanhamento e anotações; $r$ - Falta de mão-de-obra; s Problema da indústria; e, $\mathrm{t}$ - Falta de agrotóxicos registrados.

consumidos de forma similar?”. A demanda já é amplamente conhecida pelos órgãos regulatórios. A extensão de uso de alguns princípios ativos foi proposta como a medida mais facilmente aplicável, mas isso ainda não foi efetuado.

O monitoramento de insetos-praga permite a realização das pulverizações quandoé atingido o nível de dano econômico, em substituição ao uso do controle por calendário, quando se pulveriza sucessivamente, sem verificação da presença do inseto no pomar. Dos produtores entrevistados, somente um declarou não fazer monitoramento para aqueles insetos-praga que considera os principais no pomar (Tabela 3 ). Ressaltase que o monitoramento realizado adequadamente evita pulverizações desnecessárias, diminuindo custos e, principalmente, reduzindo do impacto ambiental dessas práticas, sendo apontado por TIBOLA \& FACHINELLO (2004) como fundamental no sistema PI. Contudo, TIBOLA et al. (2007) constataram que os produtores de pêssego realizam o monitoramento de pragas de maneira muito diferenciada, indo desde o levantamento semanal, conforme a recomendação, até levantamentos esporádicos.

A utilização de produtos fitossanitários pertencentes à grade de agrotóxicos da PIP é de grande importância para atingir novos mercados para o pêssego. Contudo, os produtores estudados utilizaram produtos não constantes da grade, incluindo 10 princípios ativos não autorizados (Tabela 4). Outro aspecto importante é o fato de que a totalidade dos produtores citou que um dos poucos produtos autorizados para o controle da mosca das frutas é o malathion, considerado por eles como "muito pouco eficiente", exceto quando usado no preparo de isca tóxica. Além disso, foi citado que o uso de Fentiona, utilizada por $45 \%$ dos produtores que compõe este estudo, é o produto que ainda proporciona os "melhores resultados no controle da mosca das frutas". Esses relatos indicam que há necessidade de adoção de medidas preventivas, pois o uso de produtos não recomendados pode resultar na comercialização de frutas com resíduos de agrotóxicos não autorizados para a cultura. Outro fator que pode ser estimulador do uso incorreto ou indevido de agrotóxicos é a menor importância dada à ausência de resíduos de agrotóxicos para a tomada de decisão por parte dos compradores, sendo este fator considerado menos importante em relação ao preço, aparência, sabor e aroma, conforme apontado por ROMBALDI et al. (2007).

Não se observaram diferenças entre os produtores quanto à disposição em aderir e praticar a PI em decorrência de receberem ou não assistência técnica, do tamanho da propriedade ou se exploram o mercado in natura ou indústria. O fator citado peremptoriamente por todos os produtores entrevistados como determinante para a realização de PI é visualizarem a possibilidade de uma maior remuneração pelo produto no futuro. Para a totalidade dos produtores avaliados que conhecem a PIP, os argumentos e fatos de que esse sistema protege a saúde

Tabela 3 - Realização de monitoramento de insetos-praga e doenças, tipos de armadilhas e principais insetos-praga e doenças.

\begin{tabular}{|c|c|c|c|c|c|c|c|c|c|c|c|}
\hline & \multicolumn{2}{|c|}{ Faz monitoramento de insetos-praga? } & \multicolumn{3}{|c|}{ Utiliza armadilha para qual inseto-praga? } & \multicolumn{6}{|c|}{$\begin{array}{l}\text { Quais insetos-praga e doenças considera } \\
\text { mais importantes? }\end{array}$} \\
\hline & Sim & Não & 1 & 2 & 3 & 1 & 2 & 4 & 5 & 6 & 7 \\
\hline Respostas & 19 & 1 & 15 & 16 & 3 & 17 & 13 & 2 & 3 & 1 & 1 \\
\hline$\%$ & 95 & 5 & 75 & 80 & 15 & 85 & 65 & 10 & 15 & 5 & 5 \\
\hline
\end{tabular}

1 - Mosca-das-frutas; 2 - Grapholita; 3 - Cidia; 4 - Cochonilha; 5 - Sitophilus; 6 - Bacteriose; 7 Podridão-parda. Fonte: elaboração do autor com dados da pesquisa.

Ciência Rural, v.41, n.9, set, 2011. 
Tabela 4 - Agrotóxicos utilizados na cultura do pessegueiro pelos agricultores componentes da amostra e número de agricultores que os usaram.

\begin{tabular}{lcc}
\hline Agrotóxico (Marca comercial/ Ingrediente ativo) & Número de produtores que usaram & Possui registro para a cultura \\
\hline Folicur* (Tebuconazol) & 12 & Sim \\
Dimetoato* (Dimetoato) & 10 & Não \\
Lebaycid (Fentiona) & 9 & Sim \\
Captan* (Captana) & 7 & Sim \\
Perfecthion (Dimetoato) & 7 & Não \\
Derosol (Carbendazim) & 6 & Sim \\
Dithane* (Mancozeb) & 6 & Sim \\
Manzate* (Mancozeb) & 6 & Sim \\
Amistar* (Azoxistrobina) & 3 & Sim \\
Malathion* (Malationa) & 3 & Sim \\
Rovral* (Iprodiona) & 3 & Sim \\
Bayfidan (Triadimenol) & 2 & Não \\
Imidan (Fosmet) & 2 & Sim \\
Score (Difenoconazole) & 2 & Sim \\
Alto 100 (Ciproconazol) & 1 & Sim \\
Dimexion (Difenoconazol) & 1 & Não \\
Dodex* (Dodina) & 1 & Sim \\
Orthocide* (Captana) & 1 & Sim \\
Triona* (Óleo mineral) & 1 & Sim \\
Zapp (Tifosato + sal de potássio) & 1 & Não \\
Outros (não lembravam o nome) & 4 & - \\
\hline
\end{tabular}

*Produtos pertencentes à grade de agroquímicos para PIP. Todos os produtores fizeram entre uma e duas aplicações de Glifosato no pomar Fonte: elaboração do autor com dados da pesquisa.

do produtor e do consumidor e contribui para a proteção do meio ambiente são muito importantes, mas insuficientes caso não haja resultado econômico.

\section{CONCLUSÃO}

De acordo com a hipótese, foi constatado que não há massificação do sistema PIP 'certificada'. Dentre as causas identificadas como condicionantes dessa situação estão a: 1) falta de apropriação do conceito no mercado tanto da indústria como dos consumidores, segundo a visão dos produtores componentes da amostra; 2) não diferenciação e valorização dos produtos in natura e processados oriundos da PIP; 3) poucas opções de agrotóxicos registrados especificamente para a cultura do pêssego; 4) não diferenciação na remuneração do produto oriundo da PIP em relação ao convencional, que inclui vantagens do ponto de vista de segurança do alimento (food safety) para os consumidores, proteção ambiental e saúde dos trabalhadores da cadeia agroindustrial do pêssego.

\section{REFERÊNCIAS}

BRESSER-PEREIRA, L.C. Estratégia nacional e desenvolvimento. Revista de Economia Política, v.26, n.2 (102), p.203-230, 2006.

CHEVRIN, C. Production raisonèe: defits dans le plan techologiques et commercial. Fruits, v.53, n.4, p.324-33, 2002.

EMBRAPA. Cultivo do pessegueiro. Pelotas: Embrapa Clima Temperado, 2005. (Sistemas de Produção, 4.) Disponível em: <http://sistemasdeproducao.cnptia.embrapa.br/FontesHTML/ Pessego/CultivodoPessegueiro/autores.htm>. Acesso em: 09 out. 2007.

FACHINELLO, J.C. et al. Produção integrada de pêssegos no Rio Grande do Sul: situação atual e perspectivas. In: SEMINÁRIO SOBRE PRODUÇÃO INTEGRADA DE FRUTAS, 3., 2001, Bento Gonçalves, RS. Anais... Bento Gonçalves: Embrapa Uva e Vinho, 2001. p.42-47.

FACHINELLO, J.C. et al. Produtividade e qualidade de pêssegos obtidos nos sistemas de produção integrada e convencional. Revista Brasileira de Fruticultura, v.27, n.1, p.64-67, 2005. Disponível em: <http://www.scielo.br/scielo.php?script=sci_arttext\&pid=S0100$29452005000100018 \& \operatorname{lng}=$ pt\&nrm=iso $>$. Acesso em: 12 jul. 2011. doi: 10.1590/S0100-29452005000100018.

Ciência Rural, v.41, n.9, set, 2011. 
NUNES, J.L.S. et al. Produção integrada e convencional de pêssegos cv. Marli. Revista Brasileira de Fruticultura, v.26, n.3, p.478-481, 2004. Disponível em: <http:// www.scielo.br/scielo.php?script $=$ sci_arttext\&pid $=$ S0 100 $29452004000300025 \& \operatorname{lng}=$ pt\&nrm=iso $>$. Acesso em: 12 jul. 2011. doi: $10.1590 / \mathrm{S} 0100-29452004000300025$.

PROTAS, J.F.S. Marcos referenciais da produção de maça: da concepção à implantação. In: EMBRAPA. Produção integrada de frutas: o caso da maça no Brasil. Bento Gonçalves, RS. Bento Gonçalves: Embrapa Uva e Vinho, 2003. $191 \mathrm{p}$.

REIS, A.V.; FORCELLINI, F.A. Identificação de requisitos de clientes para o projeto de um dosador de precisão para sementes miúdas. Engenharia Agrícola, v.26, n.1, p.309-320, 2006. Disponível em: $<$ http://www.scielo.br/scielo.php?script=sci_arttext\&pid=S0100$69162006000100033 \& \operatorname{lng}=\mathrm{pt} \& \mathrm{nrm}=\mathrm{iso} \& \mathrm{tlng}=\mathrm{pt}>$. Acesso em: 12 jul. 2011. doi: 10.1590/S0100-69162006000100033.

ROMBALDI, C.V. et al. Percepção de consumidores do Rio Grande do Sul em relação a quesitos de qualidade de frutas. Revista Brasileira de Fruticultura, v.29, n.3, p.681-684, 2007. Disponível em: $<\mathrm{http}: / /$ www.scielo.br/scielo.php?script=sci_arttext\&pid=S0100- 29452007000300049\&lng=pt\&nrm=iso>. Acesso em: 12 jul. 2011. doi: $10.1590 / \mathrm{S} 0100-29452007000300049$.

TIBOLA, C.S. et al. Manejo de pragas e doenças na produção integrada e convencional de pêssegos. Revista Brasileira de Fruticultura, v.27, n.2, p.215-218, 2005. Disponível em: <http://www.scielo.br/scielo.php?script=sci_arttext\&pid=S0100$29452005000200008 \& \operatorname{lng}=$ pt\&nrm=iso $>$. Acesso em: 12 jul. 2011. doi: 10.1590/S0100-29452005000200008.

TIBOLA, C.S. et al. Análise da conformidade na adoção das normas de produção integrada de pêssego. Ciência Rural, v.37, n.4, p.1149-1152, 2007. Disponível em: <http:// www.scielo.br/scielo.php? script=sci_arttext\&pid=S0103$84782007000400038 \& \operatorname{lng}=$ pt\&nrm=iso $>$. Acesso em: 12 jul. 2011. doi: $10.1590 / \mathrm{S} 0103-84782007000400038$

TIBOLA, C.S. et al. Traceability of peaches from integrated production in South Brasil. Scientia Agrícola, v.65, n.1, p.10-15, 2008. Disponível em: <http://www.scielo.br/ scielo.php? script=sci_arttext \& pid=S0103$90162008000100002 \& \operatorname{lng}=e n \& n r m=i s o>$. Acesso em: 12 jul. 2011. doi: 10.1590/S0103-90162008000100002. 